\title{
THE REACTIVITY OF ADSORBED CARBON ON VANADIUM PROMOTED RHODIUM CATALYSTS
}

\author{
T. KOERTS and R.A. VAN SANTEN \\ Schuit Institute of Catalysis, Department of Inorganic chemistry and catalysis, \\ University of Technology, Den Dolech 2, 5600 MB Eindhoven, The Netherlands
}

Received 9 May 1990; accepted 10 June 1990

Rhodium/vanadium catalyst, promoter action, adsorbed carbon, metal-carbon bond strength, carbon chain growth, quantum theoretical calculations

The hydrogenation reactivity of surface carbon deposited by $\mathrm{CO}$ decomposition was investigated for a rhodium-vanadium catalyst. It appeared that the rate of methanation of reactive surface carbon is decreased by vanadium. The reactivity towards $\mathrm{C}_{2}+$ hydrocarbons is enhanced by vanadium. The relation between stronger adsorbed carbon atoms and the formation of higher hydrocarbons is discussed. ASED calculations support the proposal that changes in metal-carbon bond strength have a significantly larger effect on the rate of methanation than on carbon chain growth.

\section{Introduction}

Adsorbed carbon atoms on group VIII metals are reaction intermediates [1-6] in the formation of hydrocarbons from synthesis gas. The formation of carbonaceous intermediates from $\mathrm{CO}$ disproportionation on these metals has been studied [7-9]. On rhodium three types of carbon [10-14] can be produced from $\mathrm{CO}$ adsorption at temperatures above $250^{\circ} \mathrm{C}: \mathrm{C}_{\alpha}, \mathrm{C}_{\beta}$ and $\mathrm{C}_{\gamma} . \mathrm{C}_{\alpha}$ species, first detected by Solymosi $[10,11]$ are hydrogenatable to methane even at room temperature. $\mathrm{C}_{\beta}$ is hydrogenatable between 200 and $300^{\circ} \mathrm{C}$ to methane. $\mathrm{C}_{\gamma}$ is less reactive graphitic like carbon hydrogenatable above $330^{\circ} \mathrm{C}$ and total removable by oxidation at $360^{\circ} \mathrm{C}$.

Rhodium catalysts are often promoted by highly oxophilic promoters [15-19] like vanadium which increases selectivity for both oxygenates and higher hydrocarbon products during synthesis gas reaction while increasing the total activity. Vanadium promotion appeared to increase the amount of $\mathrm{C}_{\alpha}$ carbon formed from $\mathrm{CO}$ disproportionation [20]. This is a function of the $\mathrm{CO}$ adsorption temperature. The reactive $\mathrm{C}_{\alpha}$ species are important intermediates which can react towards methane, $\mathrm{C}_{2}$-intermediates or $\mathrm{C}_{2} \mathrm{O}$-intermediates. The relative reactivity towards 
methane is determining for the maximum selectivity of the catalyst towards other products. In order to understand the promoting action of oxophilic promoters, it is essential to study changes in reactivity of adsorbed carbonaceous intermediates. The influence of vanadium promotion on the reactivity of adsorbed $\mathrm{C}$ atoms towards hydrogenation and carbon-carbon coupling on rhodium based catalysts is studied.

\section{Experimental}

A 3\% wt. rhodium catalyst was prepared by dry impregnation of an aqueous $\mathrm{RhCl}_{3}$ solution on silica (Grace 332). The mean rhodium particle size after reduction is $22 \AA$ as concluded from TEM and CO chemisorption. After drying and reducing at $300^{\circ} \mathrm{C}$ for 24 hours vanadium was post impregnated from a solution of $\mathrm{NH}_{4} \mathrm{VO}_{3},(\mathrm{Rh} / \mathrm{V}=3 \mathrm{~mol})$. This post impregnation did not affect the rhodium particle size. The vanadium caused a reduction of the $\mathrm{CO}$ chemisorption capacity of $50-55 \%$. This was independent of the reduction temperature between 200 and $450^{\circ} \mathrm{C}$.

Reactive $\mathrm{C}_{\alpha}$ carbon species were created during $\mathrm{CO}$ adsorption flowing 10 minutes $55 \mathrm{ml} / \mathrm{min}$ of diluted $\mathrm{CO}$ with a partial pressure of $0.5 \% \mathrm{CO}$ in $\mathrm{He}$ at 1 atm over the catalysts. The adsorption temperature was chosen in such a way that the surface coverage of reactive carbon was the same on the $\mathrm{Rh}$ and $\mathrm{RhV}$ catalysts (respectively 390 and $340^{\circ} \mathrm{C}$ ). This was confirmed with Temperature Programmed Surface Reaction experiments in which 14 percent of the total methane formation was at a temperature below $100^{\circ} \mathrm{C}$. After $\mathrm{CO}$ adsorption the catalyst was quickly cooled in a helium flow to reaction temperature at which reactivities were tested.

The hydrogenation reaction rate of the reactive carbon species was studied isothermally in a flow of $55 \mathrm{ml} / \mathrm{min}$ of $8 \%$ hydrogen in helium at $1 \mathrm{~atm}$. All gases were purified with BTS (reduced copper) and molecular sieve. Analysis was performed with a Quadrupole Mass Spectrometer in which 8 masses could be detected every second.

The influence of reactive carbon on the synthesis gas reaction was studied with transient experiments, in a system in which it was possible beside continually monitoring with a QMS, to store 16 loops of $0.3 \mathrm{ml}$ of reaction gas. The reaction gas samples were analysed afterwards with a gas chromatograph (12 meter of a wide bore plot q column) as shown in fig. 1.

The dead volume of the system was reduced as much as possible to avoid mixing of the gasses. For correct transient information it appeared to be important to create the same pressure in both flow systems before switching. After creating reactive carbon and cooling to $200^{\circ} \mathrm{C}$, the flow over the catalyst was changed to $67 \% \mathrm{H}_{2}$ in $\mathrm{He}$ or to synthesis gas $\left(\mathrm{H}_{2} / \mathrm{CO}=2\right)$, with a flow of 15 $\mathrm{ml} / \mathrm{min}$, at atmospheric pressure. During the start of the reaction 15 loops of 


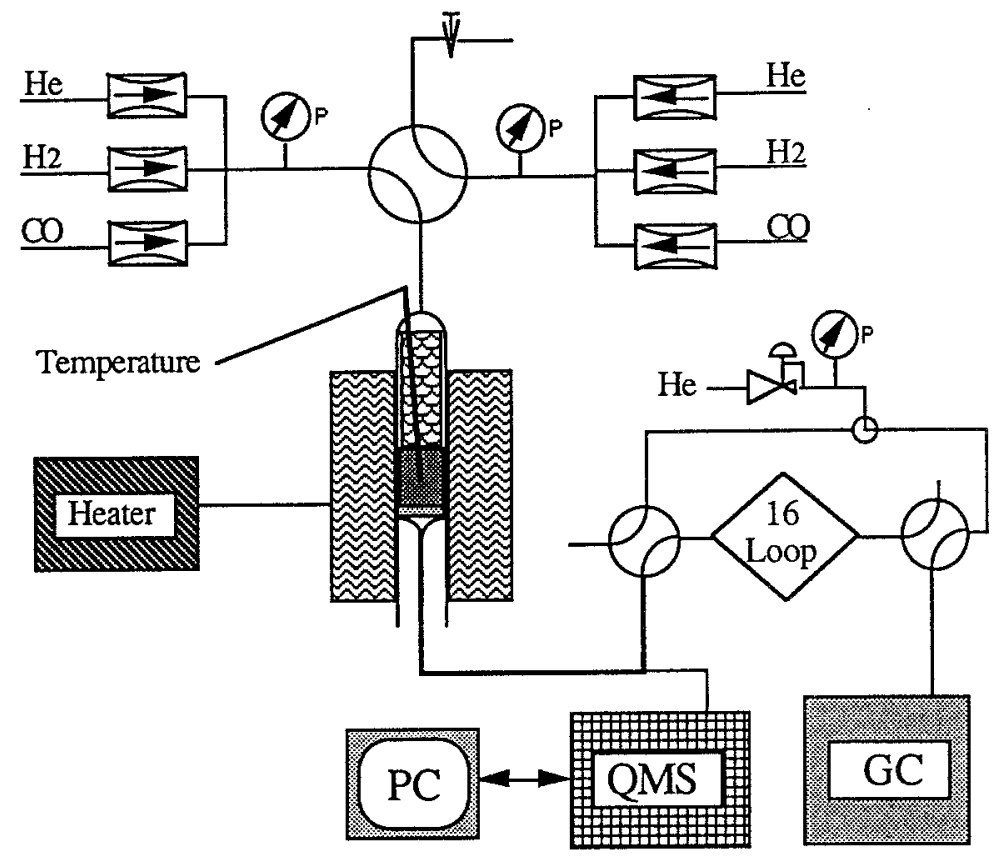

Fig. 1. Apparatus for transient response information with time based GC analysis.

reaction gas were stored and analysed afterwards. In this way a time based GC experiment could be performed. Such a system is necessary when a mass spectrometer can not separate all components or when it is not possible to measure them quantitatively.

\section{Results}

After depositing reactive carbon the hydrogenation activity towards methane was investigated at different temperatures. After switching to the diluted hydrogen flow methane curves were detected. Assuming a reaction first order in adsorbed $\alpha$ carbon, which is true for low $\Theta_{\mathrm{C}_{\alpha}}$, and the hydrogen partial pressure to be constant, the decreasing part of the methanation curve can be used to deduce the reaction rate constant. The in this way obtained $k$ values from $\mathrm{Rh}$ and $\mathrm{RhV}$ catalysts are compared in fig. 2.

The hydrogenation activity of the carbon species on the rhodium catalyst is found to be 7 times higher than on the vanadium promoted catalyst. The activation energy for this reaction appears to be about $30 \mathrm{~kJ} / \mathrm{mol}$.

Also hydrogenation experiments were performed at $200^{\circ} \mathrm{C}$. The formation of hydrocarbons from reactive carbon during this hydrogenation was studied using the time based GC equipment. In fig. 3 the initial concentrations of hydrocarbons are plotted for the $\mathrm{Rh}$ and $\mathrm{RhV}$ catalysts. 


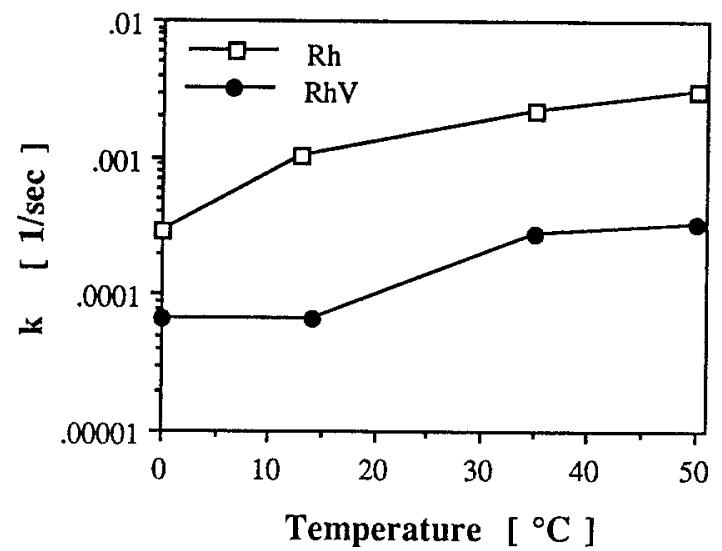

Fig. 2. Hydrogenation rate of reactive carbon on $\mathrm{Rh}$ and $\mathrm{RhV}$ as a function of temperature.

It is clear that the reactivity of the reactive carbon species towards higher hydrocarbons is increased by the vanadium promoter. This increased reactivity can not be due to a higher concentration of carbon species because the initial $\Theta_{\mathrm{C}_{\alpha}}$ was the same on both catalysts. The increased reactivity must be due to a changed intrinsic reactivity of the $\mathrm{CH}_{x}$ species. The deduced alpha values of this kind of Schulz-Flory plot are very low and methane is the main product on both catalysts. However the chance for coupling of carbon fragments is five times larger on the vanadium promoted catalyst.

The same experiment was performed using synthesis gas instead of the hydrogen helium mixture. The initial formation of hydrocarbons at $200^{\circ} \mathrm{C}$ during the start of the synthesis gas with an initial surface concentration of reactive carbon species of about 14 percent is plotted in fig. 4 .

From fig. 4 it appears that the rate of initial methane formation is about the same for both catalysts. Again more $\mathrm{C}_{2}$ hydrocarbons are produced on the vanadium promoted catalyst. This implies that the carbon-carbon bond forma-

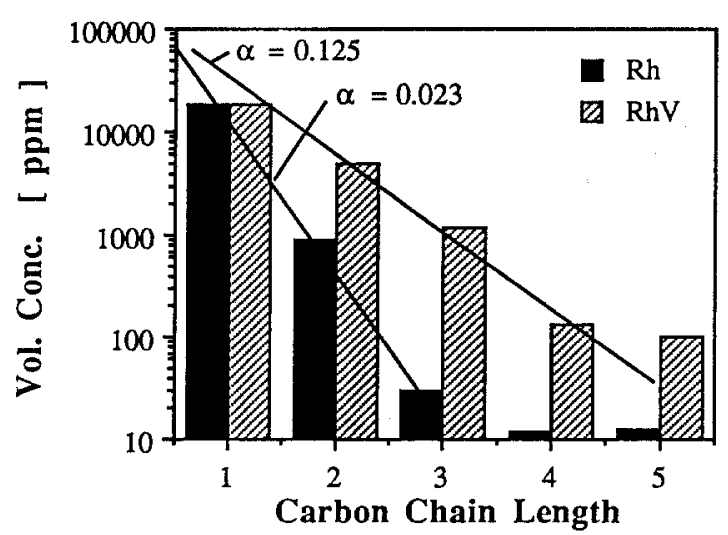

Fig. 3. The formation of hydrocarbons during hydrogenation of reactive carbon at $200^{\circ} \mathrm{C}$. 


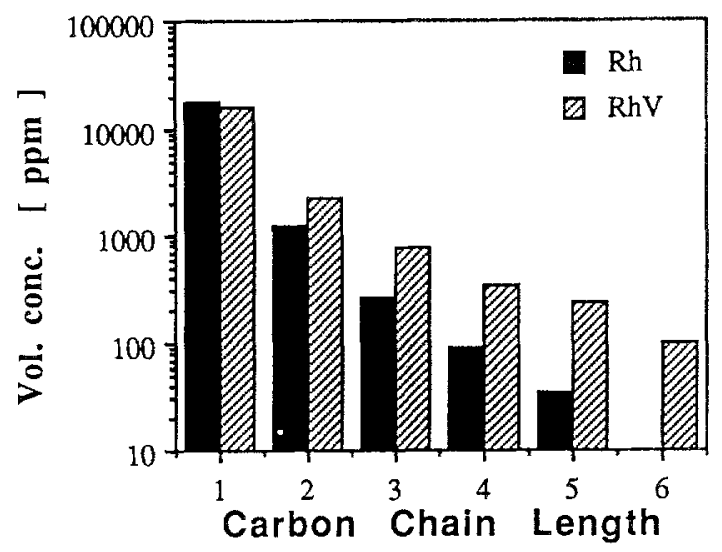

Fig. 4. The formation of hydrocarbons during the start of a reaction with synthesis gas after deposition of reactive carbon.

tion rate on the vanadium promoted catalysts at the same initial surface coverage of carbon species is enhanced. So also during the synthesis gas reaction the higher intrinsic reactivity of the adsorbed carbon species towards $\mathrm{C}_{2^{+}}$hydrocarbons is shown.

The rates of hydrocarbon formation during the start of a synthesis gas reaction was compâred with and without predeposition of reactive carbon. The results for propane to pentane are given in figs. $5 \mathrm{a}$ and $\mathrm{b}$.

$\mathrm{CO}$ adsorbing at $200^{\circ} \mathrm{C}$ on a rhodium catalyst will not produce any reactive carbon. However in the presence of hydrogen the temperature for $\mathrm{CO}$ disproportionation is lowered [21-23]. So even at $200^{\circ} \mathrm{C}$ hydrocarbons can be produced from synthesis gas. Also without predeposition the initial formation rate of hydrocarbons is higher than during the steady state reaction which exists after about $30 \mathrm{~min}$. This is due to the fact that the first CO molecules that adsorb on the rhodium surface can be relative easily dissociated because free metal ensembles, necessary for this reaction are present. On a $\mathrm{CO}$ covered rhodium surface the amount of free metal ensembles is much less, and therefore the rate of $\mathrm{CO}$ dissociation and hydrocarbon formation decreases. When $\Theta_{\mathrm{C}_{\alpha}}$ is higher after $\mathrm{CO}$ decomposition, more $\mathrm{C}_{3}$ to $\mathrm{C}_{5}$ species are formed suggesting that hydrocarbons are indeed created from $\mathrm{C}_{\alpha}$ species. For the $\mathrm{RhV}$ system it seems that there is no significant difference between the hydrocarbon formation with and without predeposition $\mathrm{CO}$. Apparently there is not much difference in the amount of reactive carbon formed at $200^{\circ} \mathrm{C}$ during the start of a synthesis gas reaction compared to $\mathrm{CO}$ deposition at $340^{\circ} \mathrm{C}$. This implicates that also in the abundance of hydrogen the formation of reactive carbon on rhodium catalysts is enhanced by vanadium [20].

From the hydrogenation experiments it appears that vanadium suppresses the reactivity of adsorbed carbon atoms. This agrees with the results on Ru of Mori et al. [23]. They investigated the rate of methanation of a pulse of $\mathrm{CO}$ in which 


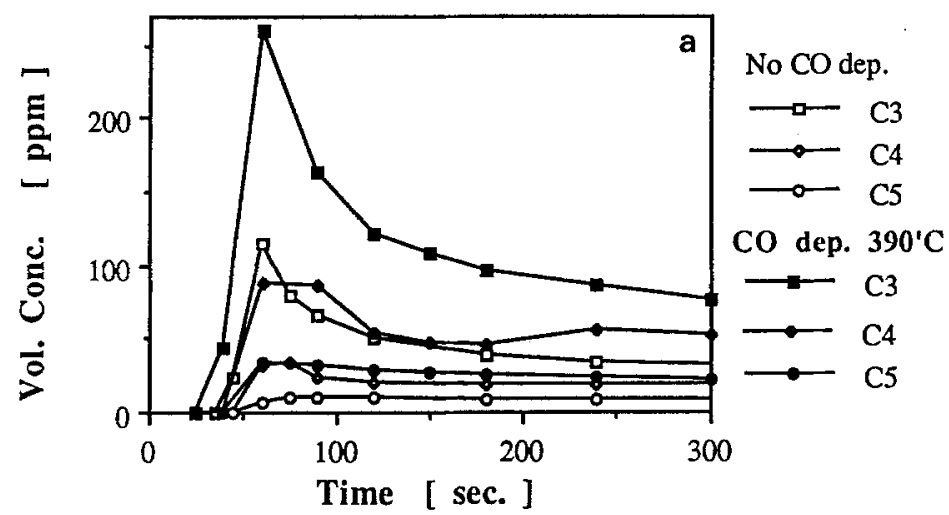

Carbon Chain formation RhV Start syngas reaction with and without reactive carbon

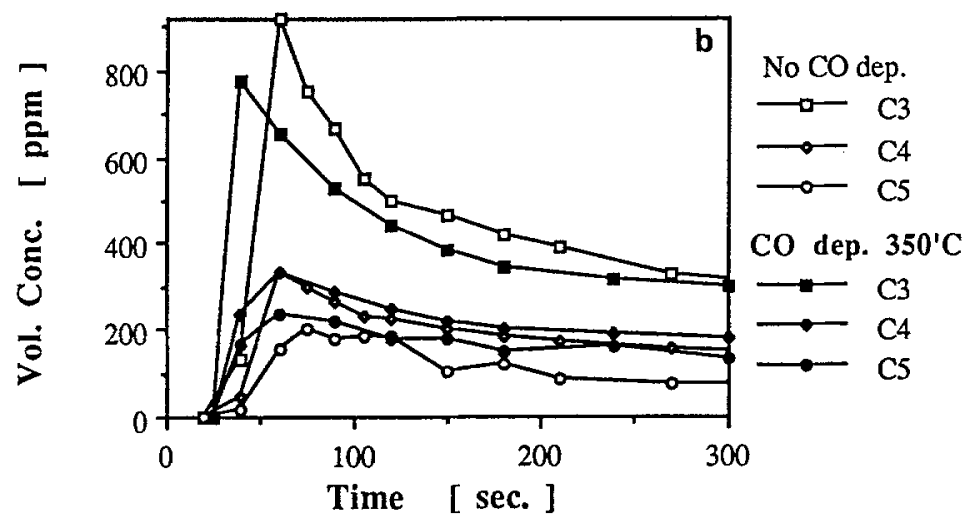

Fig. 5. Propane, butane and pentane formation during the start of a reaction with synthesis gas on a reduced catalyst and on a catalyst with $14 \%$ of reactive carbon created from CO deposition. a: Rhodium b: Rhodium/vanadium.

$k_{\mathrm{CO}}$ and $k_{\mathrm{CH}_{\mathrm{x}}}$ could be separately measured. The ratio of $k_{\mathrm{CH}_{x}} / k_{\mathrm{CO}}$ for a $\mathrm{Ru} / \mathrm{Al}_{2} \mathrm{O}_{3}$ catalyst was reduced by vanadium and molybdenum promotion.

The difficult step during hydrogenation of adsorbed $\mathrm{C}$ atoms on metal particles is related to the bond strength of the adsorbed $\mathrm{CH}_{x}$ intermediates. A slower hydrogenation is therefore probably due to a greater interaction between the carbon fragments and the metal surface. This will lead to a better selectivity for higher hydrocarbons if $\mathrm{C}-\mathrm{C}$ coupling is unaffected. This suggestion disagrees with an alternative proposed by Meriaudeau [24] who suggested that carbon-carbon bond formation is stimulated by more mobile $\mathrm{CH}_{x}$ fragments on rhodium catalysts which is enhanced by $\mathrm{TiO}_{2}$ promotion.

The relation between stronger adsorbed carbon and coupling of carbon fragments was also studied with quantum theoretical calculations using the Atom Superposition Electron Delocalization molecular orbital theory as described by 
Table 1

Adsorption energies in $\mathrm{eV}$ of $\mathrm{CH}_{x}$ fragments on $\mathrm{Ru}, \mathrm{Rh}$ and $\mathrm{Pd}$ on fcc(111) metal clusters of 40 atoms as calculated by ASED

\begin{tabular}{llll}
\hline Particle & $\mathrm{Ru}$ & $\mathrm{Rh}$ & $\mathrm{Pd}$ \\
\hline $\mathrm{CH}_{3}$ & -2.70 & -2.58 & -2.27 \\
$\mathrm{CH}_{2}$ & -4.07 & -3.77 & -2.93 \\
$\mathrm{CH}$ & -5.64 & -5.45 & -4.46 \\
$\mathrm{C}$ & -5.51 & -5.47 & -4.47 \\
\hline
\end{tabular}

Anderson $[25,26]$. The ASED method is based on Extended Huckel calculation in which a repulsion term is added. Calculations on a 40 atom cluster simulating the (111) surface of an f.c.c. crystal indicate that the activation energy for C-C coupling is rather insensitive to the metal-carbon bond strength. The bond strength as well as recombination paths have been studied by varying the number of valence electrons per metal atom. Table 1 shows the results for the optimum $\mathbf{M}-\mathrm{CH}_{x}$ bond strength for the species at their favoured adsorption sites. Figure 6 demonstrates the potential energy as a function of the reaction coordinate.

Whereas the metal-carbon bondstrength decreases in order $\mathrm{Ru}>\mathrm{Rh}>\mathrm{Pd}$, the activation "energy for carbon-carbon bond formation is not much changed. Different orbitals are involved in carbon-carbon bond formation than in metal carbon bond breaking. This result is in agreement with the LCAO calculations of Feibelman [27] which indicated that carbon binds more strongly on $\mathrm{Ru}$ than on $\mathrm{Rh}$ and $\mathrm{Pd}$. Experimentally it is found [28,29] that the selectivity for $\mathrm{C}_{2^{+}}$ hydrocarbons in synthesis gas conversion reaction decreases from $\mathrm{Ru}$ to $\mathrm{Pd}$. So for good $\mathrm{C}_{2^{+}}$hydrocarbon selectivity the interaction of adsorbed $\mathrm{C}$ fragments has to be high. The mean residence time of $\mathrm{CH}_{x}$ fragments is increased which makes

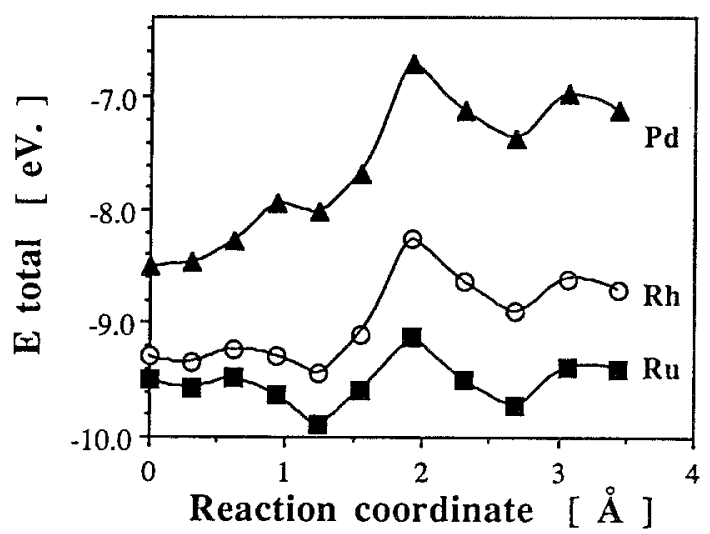

Fig. 6. Activation energy for $\mathrm{C}-\mathrm{C}$ recombination on an $\mathrm{fcc}(111)$ surface as a function of d-band occupation as calculated by ASED. The structure and parameters of $\mathrm{Ru}, \mathrm{Rh}$ and $\mathrm{Pd}$ were taken identical, only electron occupation was changed. 
the chance for $\mathrm{C}-\mathrm{C}$ bond formation greater. However this is only valid within the discussed range of metal-carbon bond strength. If the interaction of carbon atoms with metal surface becomes very large (e.g. tungsten), stable carbides can be formed which can lead to strongly reduced catalytic activity.

In conclusion, both the experimental and theoretical results show that an increased metal-carbon interaction can increase $\mathrm{C}_{2^{+}}$hydrocarbon selectivity.

\section{Acknowledgements}

We gratefully thank professor dr. ir. G.B.M.M. Marin for the opportunity to use his experimental equipment of the time based GC experiment. Further we acknowledge Johnson and Mathey for the free use of their high purity rhodium chemicals. Last but not least we thank the Dutch organisation of fundamental chemical research, SON for their financial support

\section{References}

[1] M. Araki and V. Ponec, J. Catal. 44 (1976) 439.

[2] J.G. McCarty and H. Wise, J. Catal. 57 (1979) 406.

[3] A.T. Bell, Catal. Rev.-Sci. Eng. 23 (1,2) (1981) 203.

[4] N.W. Cant and A.T. Bell, J. Catal. 73 (1982) 257.

[5] P. Biloen, J.N. Helle, F.G.A. van den Berg and W.M.H. Sachtler, J. Catal. 81 (1983) 450.

[6] R.C. Baetzold and J.R. Monnier, J. Phys. Chem. 90 (1986) 2944.

[7] J.A. Rabo, A.P. Risch and M.L. Poutsma, J. Catal. 53 (1978) 295.

[8] J.G. McCarty and H. Wise, J. Catal. 57 (1979) 406.

[9] M. McLaughlin McClory and R.D. Gonzales, J. Catal. 89 (1984) 392-403.

[10] F. Solymosi and A. Erdöhelyi, Surf. Sci. 110 (1981) L630.

[11] F. Solymosi, I. Tombácz and M. Kocsis, J. Catal. 75 (1982) 78.

[12] A. Takeuchi and J.R. Katzer, J. Catal. 82 (1983) 351.

[13] H. Orita, S. Naito and K. Tamaru, J. Catal. 111 (1988) 464.

[14] A.M. Efstathiou and C.O. Bennett, J. Catal. 120 (1989) 118.

[15] M. Ichikawa, T. Fukushima and K. Shikakura, 8th ICC Berlin, Vol. 2 (1984) 69.

[16] W.M.H. Sachtler and M. Ichikawa, J. Phys. Chem. 90 (1986) 4752.

[17] R.P. Underwood and A.T. Bell, Appl. Catal. 21 (1986) 157.

[18] B.J. Kip, P.A.T. Smeets, J.H.M.C. van Wolput, H. Zandbergen, J. and Grondelle and R. Prins, Appl. Catal. 33 (1987) 157.

[19] A.G.T.M. Bastein, H.Y. Luo, A.A.J.P. Mulder and V. Ponec, Appl. Catal. 38 (1988) 241.

[20] T. Koerts, W. Welters and R.A. van Santen, to be submitted.

[21] F. Solymosi, I. Tombácz and M. Kocsis, J. Catal. 75 (1982) 78.

[22] T. Mori, H. Masuda, H. Imal, A. Miyamota, R. Hasebe and Y. Murakami, J. Phys. Chem. 87 (1983) 3648.

[22] J.H. Siddall, M.L. Miller and W.N. Delgass, Chem. Eng. Commun. 83 (1989) 261-276.

[23] T. Mori, A. Miyamoto, N. Takahash, M. Fukagaya, H. Nizuma, T. Hattori and Y. Murakami, J. Chem. Soc. Chem. Commun. (1984) 678. 
[24] P. Meriaudeau, H. Ellestad and C. Naccache, J. Mol. Catal. 17 (2-3) (1982) 219.

[25] A.B. Anderson, J. Chem. Phys. 62 (1975) 1187.

[26] A.B. Anderson, R.W. Grimes and S.Y. Hong, J. Chem. Phys. 91 (1987)' 4245.

[27] P.J. Feibelman, Phys. Rev. B. 26 (1982) 5347.

[28] M.A. Vannice, J. Catal. 37 (1975) 462.

[29] B.W. Wojciechowski, Catal. Rev.-Sci. Eng. 30 (1988) 629. 